\title{
Mortality of fire fighters in Western Australia
}

\author{
E ELIOPULOS, ' B K ARMSTRONG,' J T SPICKETT, ${ }^{2}$ AND F HEYWORTH ${ }^{3}$
}

From the National Health and Medical Research Council Research Unit in Epidemiology and Preventive Medicine, 'Department of Medicine, University of Western Australia, Nedlands, School of Community Health, ${ }^{2}$ Division of Health Sciences, Western Australian Institute of Technology, Bentley, and Division of Occupational Health, ${ }^{3}$ Clean Air and Noise Abatement, Public Health Department, Perth, Western Australia

ABSTRACT All except $17(1.7 \%)$ of 990 fire fighters employed by the Western Australian Fire Brigade between 1 October 1939 and 31 December 1978 were successfully followed up to 31 December 1978. Mortality from all causes was less than expected (SMR 0.80 with 95\% confidence interval 0.67 to 0.96 ). There was evidence of the healthy worker effect but none that mortality increased with increasing duration of employment. A small proportional excess of deaths from road traffic accidents (SPMR 1.66) appeared to be unrelated to fire service. Deaths from other accidents, poisonings, and violence were significantly less than expected (SMR 0.35 with $95 \%$ confidence interval $0 \cdot 10$ to 0.90 ) and may indicate an effect of training and experience on accident proneness. There was no evidence of increased mortality from cardiovascular or respiratory disease, or from any other cause.

Concern is frequently expressed at the hazards of fire fighting both with respect to accidental injury and death, and illness or death as a result of inhalation of noxious substances (see, for example, Gannon $^{1}$ ). Accidents undoubtedly do occur, and acute changes in lung function can be demonstrated (see, for example, Musk $e t a l^{2}$ ), but the chronic effects of fire fighting and its effect on mortality are less clear.

Three studies have reported on the mortality of cohorts of fire fighters compared with that of appropriate general populations. Mastromatteo, on follow up of 1039 Ontario fire fighters, found a significant increase in mortality from all causes $(270$ deaths, SMR 119), mainly due to deaths from accidents and violence (SMR 140) and cardiovascular and renal disease (SMR 135) ${ }^{3}$ On the other hand, Guthrie found no increase in mortality from all causes (60 deaths, SMR 55) in 4379 Los Angeles fire fighters or coronary heart disease (SMR 53) but found a proportional increase in deaths from accidents (SMR 79). ${ }^{4}$ Later, Musk et al also found a lower than expected overall mortality ( 2470 deaths, SMR 91 ) in 5655 Boston fire fighters and no increase in mortality from cardiovascular disease (SMR 86). ${ }^{5}$ Active fire fighters showed an increase in mortality from accidents (SMR 134). None of these studies showed an increase in mortality from respiratory disease.

Received 31 January 1983

Accepted 26 April 1983
Evidence of chronic morbidity has also been sought. There are inconsistent indications of more rapid loss of lung function in fire fighters than other men. ${ }^{6-8} \mathrm{~A}$ higher than expected prevalence of coronary disease has also been reported,' but a recent study found no difference in incidence of new coronary events between fire fighters and other comparable men. ${ }^{10}$

This apparent conflict over the chronic effects of fire fighting suggested to us that a further cohort study of mortality would be justified.

\section{Methods}

\section{DEFINITION OF COHORT}

Our cohort consisted of all men employed as permanent full time fire fighters by the Western Australian Fire Brigade (WAFB) between 1 October 1939 and 31 December 1978. 1 October 1939 marked the beginning of a superannuation scheme through which the cohort was identified. Men in employment on this date and first employed subsequently were all included; they totalled 990. The only data consistently available on all men were date of birth, date joined the WAFB, and date left the WAFB.

FOLLOW UP

Follow up was undertaken retrospectively to 31 
December 1978; 639 men were still employed by the WAFB on that date. Follow up of the remainder was achieved by a search of the Western Australia state death registers for all years from 1939 to 1978 , the Western Australia state electoral roll current in 1979, motor vehicle drivers' licence records current in 1979, public hospital patient indexes, union records, the telephone directory, and by questioning retired fire fighters. A total of 116 deaths were identified and 204 retired fire fighters were found to be alive and resident in Western Australia. A further 14 men had emigrated and $17(1.7 \%)$ were untraced.

Copies of death certificates were obtained for all dead firemen; they included the underlying cause of death as assigned and coded at the time of death.

\section{ANALYSIS}

Person-years of follow up distributed by era of first employment, calendar period of follow up and age were calculated by Man Years Computer Language" from the date of first employment or 1 October 1939, whichever was later, to death, emigration, or 31 December 1978, whichever was earlier. The 17 men lost to follow up were treated as surviving to 31 December 1978. Expected numbers of deaths were calculated within 10 year age groups in the calendar periods $1940-52,1953-7,1958-62$, $1963-7,1968-72$, and $1973-8$ by use of average mortality rates for each cause of death in all WA men in the periods 1951-7 (used for person-years accumulated from 1940 to 1957), 1958-62, 1963-7, 1968-72, and 1973-8.

Proportional mortality analysis was also undertaken. For deaths occurring in each 10 year age group and time period, expected numbers of deaths by cause were calculated from the proportional distribution, by cause, of all deaths in WA men in the appropriate age and time group.

Observed and expected numbers of deaths were compared by calculation of standardised mortality ratios (SMRs) and standardised proportional mortality ratios (SPMRs). Ninety five per cent confidence intervals about SMRs and SPMRs were calculated from the table given by Haenszel et al. ${ }^{12}$

\section{Results}

\section{ALL CAUSES OF DEATH}

A total of 16876 person-years of follow up were accumulated by fire fighters in the cohort; 116 deaths were observed, 143.7 expected (SMR $=0.80$ with $95 \%$ confidence interval 0.67 to 0.96 ). Table 1 shows deaths from all causes distributed by era of first employment, duration of follow up since first employment, and duration of employment.

The SMR for those in employment at the start of follow up, 0.84 , was a little higher than in those followed up from first employment at a later date $(0 \cdot 74)$. There was little evidence of a tendency for SMRs to rise with time since first employment except after 30 years. Nor did SMRs rise with duration of employment. On the contrary, there was a significant excess of deaths in those employed for less than one year (6 deaths, SMR 3.37). This was an unexpected finding and was uncovered somewhat accidentally during analysis of the data.

The six deaths in fire fighters employed for less than one year were caused by road traffic accidents (3 observed, 0.23 expected), other accidents, poisonings, and violence ( 1 observed, a suicide, 0.31 expected), and malignant neoplasms of other than

Table 1 Numbers of deaths from all causes and SMRs in fire fighters distributed by era of first employment, time since first employment, and duration of employment

\begin{tabular}{|c|c|c|c|}
\hline & \multirow[t]{2}{*}{ No of deaths } & \multicolumn{2}{|l|}{$S M R$} \\
\hline & & Point estimate & $95 \%$ Confidence interval \\
\hline $\begin{array}{l}\text { Era of first emp } \\
1939 \text { or earlier } \\
\text { After } 1939\end{array}$ & $\begin{array}{l}83 \\
33\end{array}$ & $\begin{array}{l}0 \cdot 84 \\
0.74\end{array}$ & $\begin{array}{l}0.67-1.05 \\
0.52-1.03\end{array}$ \\
\hline $\begin{array}{l}\text { Time since first } \\
0-9 \\
10-19 \\
20-29 \\
30-39 \\
\geqslant 40\end{array}$ & $\begin{array}{r}9 \\
8 \\
13 \\
28 \\
58\end{array}$ & $\begin{array}{l}0.73 \\
0.63 \\
0.53 \\
0.84 \\
0.95\end{array}$ & $\begin{array}{l}0.33-1 \cdot 39 \\
0.27-1.24 \\
0.28-0.91 \\
0.56-1.22 \\
0.73-1.24\end{array}$ \\
\hline $\begin{array}{l}\text { Duration of emp } \\
<1 \\
1-9 \\
10-19 \\
20-29 \\
\geqslant 30\end{array}$ & $\begin{array}{r}6 \\
15 \\
10 \\
19 \\
66\end{array}$ & $\begin{array}{l}3.37 \\
0 \cdot 88 \\
0 \cdot 83 \\
0.97 \\
0 \cdot 71\end{array}$ & $\begin{array}{l}1.24-7.08 \\
0.49-1.45 \\
0.40-1.53 \\
0.58-1.55 \\
0.56-0.90\end{array}$ \\
\hline
\end{tabular}


Table 2 Numbers of deaths and SMRs in fire fighters by cause of death

\begin{tabular}{lcll}
\hline Cause of death & No of deaths & \multicolumn{1}{l}{ SMR } & \\
\cline { 3 - 4 } & & Point estimate & $95 \%$ Confidence interval \\
\hline All neoplasms: & 30 & $1 \cdot 09$ & $0 \cdot 74-1 \cdot 56$ \\
Respiratory cancer & 7 & $0 \cdot 84$ & $0 \cdot 33-1 \cdot 71$ \\
Other cancers & 23 & $1 \cdot 21$ & $0 \cdot 77-1 \cdot 82$ \\
Circulatory disease: & 55 & $0 \cdot 78$ & $0 \cdot 60-1 \cdot 01$ \\
Ischaemic heart disease & 39 & $0 \cdot 84$ & $0 \cdot 60-1 \cdot 14$ \\
Other circulatory disease & 16 & $0 \cdot 65$ & $0 \cdot 38-1 \cdot 07$ \\
Respiratory disease: & 3 & $0 \cdot 66$ & $0 \cdot 26-1 \cdot 36$ \\
Bronchitis, asthma, and emphysema & 4 & $0 \cdot 65$ & $0 \cdot 13-1 \cdot 90$ \\
Other respiratory disease & 12 & $0 \cdot 67$ & $0 \cdot 18-1 \cdot 72$ \\
Accidents, poisonings, and violence: & 8 & $0 \cdot 63$ & $0 \cdot 33-1 \cdot 10$ \\
Road traffic accidents & 4 & $1 \cdot 04$ & $0 \cdot 45-2 \cdot 05$ \\
Other accidents, poisonings, and violence & 12 & $0 \cdot 35$ & $0 \cdot 38-1 \cdot 30$ \\
All other causes of death $\dagger$ & 116 & $0 \cdot 74$ & $0.67-0.96$ \\
All causes of death & & 0.80 & 0.96 \\
\hline
\end{tabular}

"Expressed as the observed to expected ratio without multiplication by 100 .

†All other ICD-8 chapters, each with three or fewer observed deaths.

Table 3 Numbers of deaths in fire fighters and SPMRs (standardised proportional mortality ratios) by cause of death

\begin{tabular}{|c|c|c|c|}
\hline \multirow[t]{2}{*}{ Cause of death } & \multirow[t]{2}{*}{ No of deaths } & \multicolumn{2}{|l|}{$S P M R^{*}$} \\
\hline & & Point estimate & $95 \%$ Confidence interval \\
\hline $\begin{array}{l}\text { Neoplasms: } \\
\text { Respiratory cancer } \\
\text { Stomach cancer } \\
\text { Intestinal cancer } \\
\text { Other digestive cancer } \\
\text { Genitourinary cancer } \\
\text { Lymphohaematopoietic cancer } \\
\text { Other cancers } \\
\text { Circulatory diseases: } \\
\text { Ischaemic heart disease } \\
\text { Other circulatory diseases } \\
\text { Respiratory diseases: } \\
\text { Bronchitis, asthma, and emphysema } \\
\text { Other respiratory diseases } \\
\text { Accidents, poisonings, and violence: } \\
\text { Road traffic accidents } \\
\text { Other accidents, poisonings, and violence } \\
\text { All other causes of death } \dagger\end{array}$ & $\begin{array}{r}30 \\
7 \\
5 \\
4 \\
3 \\
4 \\
3 \\
4 \\
55 \\
39 \\
16 \\
7 \\
3 \\
4 \\
12 \\
8 \\
4 \\
12\end{array}$ & $\begin{array}{l}1.37 \\
1.04 \\
2.02 \\
1.59 \\
0.88 \\
1.08 \\
1.88 \\
2.97 \\
0.94 \\
1.02 \\
0.78 \\
0.77 \\
0.73 \\
0.81 \\
0.95 \\
1.66 \\
0.53 \\
0.87\end{array}$ & $\begin{array}{l}0.93-1.36 \\
0.42-2.13 \\
0.65-4.70 \\
0.43-4.07 \\
0.18-2.58 \\
0.29-2.76 \\
0.39-5.50 \\
0.81-7.60 \\
0.72-1.22 \\
0.73-1.39 \\
0.45-1.26 \\
0.31-1.59 \\
0 \cdot 15-2.13 \\
0.22-2.07 \\
0.49-1.66 \\
0.72-3.27 \\
0.14-1.35 \\
0.45-1.52\end{array}$ \\
\hline
\end{tabular}

*Expressed as the observed to expected ratio without multiplication by 100 .

tAll other ICD-8 chapters, each with three or fewer observed deaths.

the respiratory system ( 2 observed, $0 \cdot 24$ expt of which both were cerebral astrocytomas.

\section{SPECIFIC CAUSES OF DEATH: SMRS}

Table 2 shows numbers of deaths and SMRs in broad categories of cause of death. Only SMRs for neoplasms (specifically, cancers other than respiratory cancer) and road traffic accidents differed at all from the general patterns of SMRs less than unity; neither was significantly greater than $1 \cdot 0$. The SMR for "other accidents, poisonings, and violence" was significantly less than 1.0 (4 deaths observed, SMR $0 \cdot 35$ ).

Within the "all other causes of death" category, only one stood out-two deaths from congenital anomalies, 0.40 expected, giving an SMR of 5.0 with $95 \%$ confidence interval $0 \cdot 60$ to $18 \cdot 0$. Both of these deaths were attributed to coarctation of the aorta, a surprising, but almost certainly chance, coincidence.

For neither the "other cancers," nor road traffic accidents, was there any indication that the SMRs increased with increasing duration of employment. For both, the most notable excesses were in those employed for less than one year (see above). The low SMR for other accidents, poisoning, and violence was confined to those employed for 10 years or more (SMRs 0.93 for less than 10 years' employment and 0.12 for 10 or more years). 
SPECIFIC CAUSES OF DEATH: SPMRS

SPMRs were calculated to provide some adjustment for the operation of the healthy worker effect ${ }^{13}$ on cause specific SMR estimates suggested by the low SMR for all causes. Table 3 shows numbers of deaths and SPMRs by cause of death; additional categories of cancers were included in this table because of the relatively high SMR for other cancers in table 2 .

No single SPMR was significantly different from unity. For all cancers other than respiratory cancer (the category used in table 2) the SPMR was 1.52 with $95 \%$ confidence interval $0 \cdot 97-2 \cdot 29$. This overall excess was not concentrated in any one cancer site. The relatively high SPMR for "other cancers" was based on three cerebral tumours (two in men employed for less than one year, as mentioned above) and one death from carcinomatosis with unspecified primary site. The relative excess of deaths from road traffic accidents (SPMR 1.66) included only one death in the course of duty"caused when fire engine he was driving collided with motor wagon." None of the other deaths from accidents, poisonings, and violence occurred at work; three were suicides.

\section{Discussion}

Not unexpectedly, the SMR for all causes of death in this study $(0 \cdot 80)$ was significantly less than $1 \cdot 0$. This may be due, in part at least, to the untraced men and the healthy worker effect. ${ }^{13}$ The untraced men, $1.7 \%$ of the total, were treated in the analysis as if alive and resident in Western Australia at the end of the follow up period. It is unlikely that we would have missed any deaths but a proportion of the untraced may have left the state, thus leading to an overestimate of person-years.

Evidence of the healthy worker effect may be seen in table 1 . The SMR in men already employed as firemen when the follow up began was higher $(0 \cdot 84)$ than in men who joined the WAFB during the course of follow up (0.74). The healthy worker effect ought to be more evident in the latter group because of the high standard of physical fitness required on entry to the brigade. In addition there was some evidence that the SMRs approached 1.0 with increasing duration of follow up.

There is virtually no evidence in these data of an adverse effect of fire fighting on mortality. The SMRs did not increase with increasing duration of service, and there was no evidence of increased mortality from ischaemic heart disease, chronic respiratory disease, accidents, or respiratory cancer. The small and statistically non-significant increase in proportional mortality from road traffic accidents could not be readily attributed to fire service because only one of the accidents occurred at work.

Cancer, other than respiratory cancer, was the only other cause of death which stood out among the generally low rates. The excess, however, was small, not statistically significant, and distributed among a number of cancer sites. It is doubtful whether any importance should be attached to it.

The apparently low mortality from other accidents, poisonings, and violence may be of interest. It was mainly evident in men who had served more than 10 years, a fact which adds plausibility to a specific association with fire service. One might speculate that the training of fire fighters, and their experience in extricating others from hazardous situations, may make them more careful and better able to handle potentially life threatening circumstances.

Our results agree with those of Guthrie $^{4}$ and Musk $e^{~} \mathrm{al}^{\mathrm{s}}$ in showing a lower overall mortality rate in fire fighters and no evidence of increased mortality from ischaemic heart disease or respiratory disease. They are anomalous in not showing an increased mortality from accidents. It would not be unreasonable to suggest, however, that hazards vary from one community to another or that safety standards vary from one fire service to another. It may be that Western Australia is a particularly hazard free community (the other studies were all North American) or that the safety standards of the WAFB are particularly high. Our results also cover a later period, on average, than those of Mastromatteo $^{3}$ and Musk $e a{ }^{5}$ (which had follow up from 1921 to 1953 and 1915 to 1975 respectively) and may indicate an improvement in safety standards since then.

The help of the Western Australia Fire Brigade is gratefully acknowledged.

Requests for reprints to: Dr B K Armstrong, University Department of Medicine, Queen Elizabeth II Medical Centre, Nedlands 6009, Western Australia.

\section{References}

' Gannon JA. Union denounces high mortality among fire fighters as disgrace. Occup Health Saf 1980;10:6-7.

${ }^{2}$ Musk AW, Smith TJ, Peters JM, McLaughlin E. Pulmonary function in fire fighters: acute changes in ventilatory capacity and their correlates. Br J Ind Med 1979;36:29-34.

${ }^{3}$ Mastromatteo E. Mortality in city firemen II. A study of mortality in firemen of a city fire department. American Medical Association Archives of Industrial Health 1959;20:227-33.

- Guthrie LC. Los Angeles firemen cardiovascular disease survey. Report to the Department of Preventive Medicine, School of 
Medicine, and School of Public Health, University of California, Los Angeles. Los Angeles: University of California, 1970.

${ }^{5}$ Musk AW, Monson RR, Peters JM, Peters RK. Mortality among Boston fire fighters, 1915-75. Br J Ind Med 1978;35:104-8.

- Peters JM, Theriault GP, Fine LJ, Wegman DH. Chronic effect of fire fighting on pulmonary function. $N$ Engl $J$ Med 1974;91:1320-2.

' Musk AW, Peters JM, Wegman DH. Lung function in fire fighters I. A three year follow-up of active subjects. Am J Public Health 1977;67:626-9.

${ }^{8}$ Sparrow D, Bosse R, Rosner B, Weiss ST. The effect of occupational exposure on pulmonary function. A longitudinal evaluation of fire fighters and non-fire fighters. Am Rev Respir Dis
1982;125:319-22.

9 Barnard RJ, Weber JS. Carbon monoxide: hazard to fire fighters. Arch Environ Health 1979;34:255-7.

${ }^{10}$ Dibbs E, Thomas HEJ, Weiss ST, Sparrow D. Fire fighting and coronary heart disease. Circulation 1982;65:943-6.

" Hill ID. Computing man-years at risk. Br J Prev Soc Med 1972; 26:132-4.

12 Haenszel W, Loveland D, Sirken MG. Lung cancer mortality as related to residence and smoking histories. J Natl Cancer Inst 1962;28:947-1001.

${ }^{13}$ McMichael AJ. Standardized mortality ratios and the "healthy worker effect": scratching beneath the surface. JOM 1976; 18: 165-8. 